\title{
NUTRIGENOMICA: ENLACE ENTRE NUTRICIÓN GENES Y SALUD
}

\author{
PatriciaTabacchi Bolívar ${ }^{I}$ \\ Fred García Alayo ${ }^{2}$
}

\begin{abstract}
RESUMEN
La dieta es un factor ambiental que afecta al estado nutricional y esto se ve reflejado en desordenes metabólicos que conducen al desarrollo de varias enfermedades. Actualmente, la nutrición y la genética unen conocimientos y se integran en un área de estudio, la denominada genética nutricional. En el presente artículo, se revisa el concepto de Nutrigenómica y se brinda algunos ejemplos de la profunda interrelación existente entre alimentación, salud y genes.
\end{abstract}

Palabras claves: Nutrigenómica, expresión genética, nutrición.

\section{SUMMARY}

Diet is an environmental factor that affects the nutritional status and this is reflected in metabolic disorders that lead to the development of various diseases. Currently, nutrition and genetics come together and integrate knowledge in a study area, the so-called nutritional genetics. In this article, we review the concept of Nutrigenomics and provide some examples of the profound interrelationship between food, health and genes.

Key words: Nutrigenomics, gene expression, nutrition.

\section{INTRODUCCION}

La Biología Molecular es una disciplina con personalidad propia, sus conceptos y tecnologías han contribuido notablemente al desarrollo de todas las restantes ramas de la biología moderna. Sin embargo, la Nutrición se ha ido incorporando muy lentamente a las posibilidades que brinda la Biología Molecular.

La pasada década ha sido testigo de la gran interacción que se está estableciendo entre ambas disciplinas y de la comprensión alcanzada sobre la importancia de los nutrientes no solo en el crecimiento, desarrollo y mantenimiento de los tejidos, sino también en nuevas dimensiones como son su relación con la expresión génica, efectividad de la respuesta inmune, la prevención del daño celular y su interacción con enfermedades crónicas e infecciosas.

\section{Interrelación}

La interrelación entre nutrición y expresión génica se expresa en 2 sentidos: la influencia que los nutrientes ejercen sobre la expresión génica y la síntesis de proteínas, y la influencia de la expresión génica sobre los requerimientos nutricionales. Pueden resumirse en
3 los aspectos fundamentales que deben ser abordados para comprender esta interacción:

- Cuáles genes son regulados por factores nutricionales.

- Cómo la dieta y los nutrientes en particular ejercen la regulación de la expresión de estos genes.

- Cómo está involucrada la expresión de los genes en el metabolismo y el aprovechamiento de los nutrientes (Cagigas, 2002; Gómez, 2002)

La expresión génica es un proceso muy complejo mediante el cual se logra la síntesis de una cadena polipeptídica a partir de la información hereditaria contenida en el gen correspondiente, lo que constituye el llamado dogma central de la genética-perfeccionado en las últimas décadas con los conocimientos aportados por la Biología Molecular. La información genética en el ADN es transcripta a una molécula de ARNm (transcripto primario), la cual es procesada para dar una molécula de ARN maduro. Este ARNm es transportado desde el núcleo hasta el citoplasma donde es traducido para la síntesis de una proteína. Potencialmente la expresión de un gen puede ser regulada en cualquiera de las etapas que transcurren desde su transcripción hasta la síntesis de la proteína activa, este estricto y 
variado sistema de control está influenciado por el estado nutricional del individuo (Cagigas, 2002; Mead, 2008)

Por otro lado la nutrición es un proceso complejo que permite el ciclo de la vida, al que abastece de sustancias que participan como fuentes de energía en la estructura celular y para el control del metabolismo, para mantener así la función y la homeostasis corporal. Según algunos autores, el estado nutricional es un fenotipo resultado de la interacción entre la información genética de cada persona, su medio físico, biológico, emocional y social. Los factores ambientales involucrados en la homeostasis de los organismos son varios, entre los que destaca la dieta, que influye en la incidencia de enfermedades crónicas comunes. Los alimentos ingeridos tienen miles de sustancias biológicamente activas, muchas de las cuales pueden tener un potencial benéfico para la salud $\mathrm{y}$, en algunos casos especiales, incluso pueden ser deletéreos (Belén, 2007; Cagigas, 2002; Pérez, 2006).

De esta manera, la salud o la enfermedad dependen de la interacción entre la genética y el medio, lo que da lugar al fenotipo.

Los componentes de la dieta pueden alterar la expresión genómica de manera directa o indirecta. Así, celularmente hablando, los nutrientes pueden:

- Actuar como ligando para la activación de factores de transcripción que favorezcan la síntesis de receptores.

- Metabolizarse por rutas metabólicas primarias o secundarias, y de ese modo alterar la concentración de substratos o intermediarios.

- Influir de modo positivo o negativo en las rutas de señalización. (Fig. 1).

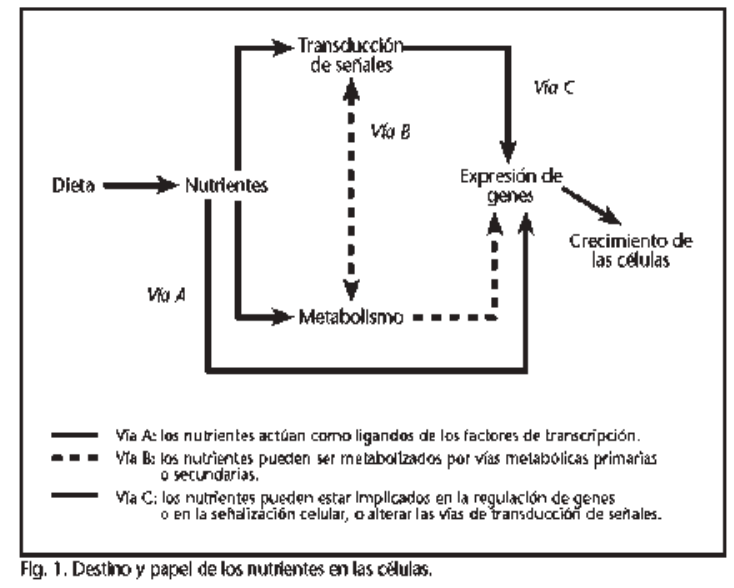

\section{Metabolismo y expresión genética:}

Los ácidos grasos, las vitaminas y las hormonas son claros ejemplos de su accionar metabólico en la expresión de los genes, así tenemos:
Que los ácidos grasos, se metaboliza mediante la ruta de la beta-oxidación para producir energía celular. La alteración del balance energético intracelular puede alterar indirectamente la expresión genética mediante cambios en la homeostasis de dinucleótido de nicotinamida y adenina (NAD, en sus siglas en inglés) celular. La reoxidación de NAD está asociada con la actividad de la cadena de transporte electrónico de la mitocondria, y es un cofactor para proteínas involucradas en la remodelación cromosómica. Por otro lado, el proceso de remodelación cromosómica tiene consecuencias a corto y largo plazo para la regulación genética mediante reacciones, como la acetilación de las histonas o la mutilación del ácido desoxirribonucleico (ADN) que altera su acceso, y, por tanto, su regulación, en eucariotas.(Cagigas, 2002, Bourges, 2003).

Algunas moléculas de la dieta pueden ser ligandos para receptores nucleares. Muchos, pero no todos los genes involucrados en el metabolismo de los ácidos grasos, están regulados por uno de los 3 miembros de la familia de receptores activados por el proliferador de peroxisomas (PPAR, PPAR, PPARgamma). Un hallazgo sorprendente fue que los ácidos grasos, palmítico, oleico y araquidónico, y ciertos eicosanoides, como el ácido 8(S) hidroxieicosatraenoico, eran ligandos para los PPAR, de modo que estos receptores nucleares actúan como sensores para los ácidos grasos. Los sensores de lípidos a menudo heterodimerizan con un receptor $\mathrm{X}$ retinoide, cuyo ligando se deriva de otro agente químico de la dieta, el retinol. Otros componentes de la dieta, como la genisteína, la vitamina A, o la hiperforina, se unen directamente a los receptores nucleares y alteran la expresión genética. La concentración de cualquier ligando dependerá de combinaciones específicas de alelos en genes que codifiquen proteínas de las rutas enzimáticas. El número de individuos heterocigóticos puede variar de una subpoblación respecto a otra, lo que constituye un principio básico en la genómica nutricional. Algunos cereales, como el arroz, contienen inositol hexafosfato, capaz de inhibir la transformación celular inducida por el factor de crecimiento celular por sus acciones en la fosfatidilinositol 3-cinasa. El resveratrol, el fenetil isotiocianato, la genisteína o los retinoides también afectan a las rutas de señalización celular. Algunos nutrientes como el hierro ejercen unos controles postranscripcional de la expresión del receptor de la transferrina y de la ferritina, en ambos casos ejercido a través de elementos regulatorios situados en las regiones no traducidos (UTR) de los respectivos ARNm. (Cagigas, 2002; Palou et al, 2004; Pérez, 2006, Belén, 2007).

Los aminoácidos también ejercen un importante control sobre la expresión de algunos genes como los de la asparagina sintetasa, produciendo un incremento de la proporción de transcripción y de la estabilidad del 
RNA mensajero. Otras 2 enzimas, la dihidrofolato reductasa y la timidilato sintasa, son capaces de regular la traslación por su unión a una parte del ARNm que incluye al codon AUG.(Gómez, 2007; Mead, 2008).

\section{Evolución de las ciencias nutricionales}

El conocimiento de la importancia de los alimentos ha ido acompañando al hombre mismo durante su evolución, desde un simple consumo para saciar el hambre hasta un consumo de alimentos seleccionados para mejorar el estado de salud o para la prevención de alguna enfermedad, hoy en día la Nutrigenómica es una ciencia que ha establecido que - tal como ocurre con algunas drogas- sólo algunos segmentos de la población responderán positivamente a intervenciones nutricionales específicas. La ciencia nos plantea que alimentos y sus respectivas unidades o dosis de consumo que pudieran ser positivos para algunas personas podrían no tener efectos en otras. Peor aún, las dosis no adecuadas de alimentos "saludables" también tener riesgos o actuar negativamente.(Pérez, 2006, Pisabarro, 2006).

Para algunos científicos resulta atractivo concentrar sus análisis en los efectos de un solo nutriente, mientras que para los investigadores en Nutrigenómica el enfoque real debe ser sobre el impacto de múltiples desequilibrios nutricionales sobre el genoma (tanto por excesos como por deficiencias).(Gómez, 2007; Pérez et al 2005) (Fig. 2).

Conocer y descifrar la inocuidad de los alimentos pasa a ser entonces un desafío prioritario para el mundo científico y para los propios productores.

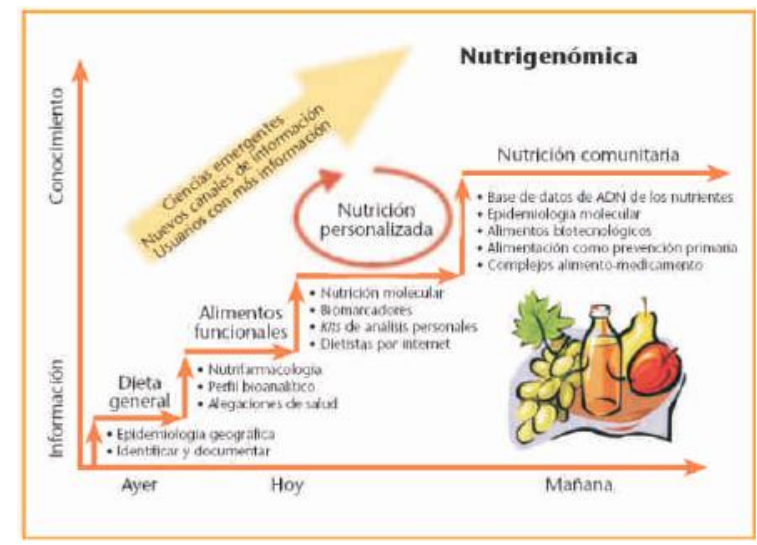

Fig.2 Evolución de las Ciencias Nutricionales

\section{En un futuro próximo:}

Sólo en algunos años la información genética podrá utilizarse en el tamizaje de poblaciones o grupos de riesgo para determinar la susceptibilidad individual a desórdenes de alta prevalencia, como enfermedades cardiovasculares, diabetes y cáncer, para así permitir aplicar medidas de prevención primaria y secundaria.

Tendrá lugar el descubrimiento de más polimorfismos de un solo nucleótido y la identificación de muchos genes susceptibles para desórdenes complejos, con la consiguiente implantación de regímenes dietéticos personalizados. Los avances tecnológicos paralelos en genética y nutrición podrán evidenciar la influencia de unos sobre los otros y viceversa de tal forma que alcancemos una homeostasia en el ciclo de vida de una persona que garanticen un buen estado de salud.

\section{LITERATURA CITADA}

BELEN M. 2007. Nutrigenómica, Obesidad y Salud Publica. Re. Esp. Salud Pública.81:475-487.

BOURGES RH. 2003. La nutriología a partir de la «doble hélice». Rev Invest. Clin. 55:220-6.

CAGIGAS Reig Ada. 2002.Biología Molecular y Nutrición. Revista Cubana Aliment Nutr (1):69-76

GOMEZ AYALA A. 2008. Nutrigenómica y Nutrigenética. Offarm.2007;26:4.

MEAD N. Nutrigenómica. Interfase entre genoma y alimentos. Ciencia \& Trabajo 28:24-32

PALOU A, Bonet ML, Picó C, Rodríguez AM. 2004.Nutrigenómica y obesidad. Rev Med Univ Navarra. 48:36-48.

PÉREZ Bravo F. 2006. Genómica nutricional. La era molecular de la nutrición. Nutrición 21. 15:14-5.

PÉREZ Cruz E, et.al. 2005. Genómica nutricional: perspectiva para el futuro. Rev. Endocrinol Nutr.;13:190-6.

PISABARRO R. 2006 . Nutrigenética y Nutrigenómica: La revolución sanitaria del nuevo milenio. Implicaciones clínicas en síndrome metabólico y diabetes tipo 2. Rev Med Urug. 22:100-7. 